\title{
Adaptation and Validation of the Portuguese Peabody Developmental Motor Scales - 2 edition: A Study With Children Aged 12 to 48 Months
}

Miguel Rebelo ( $\nabla$ miguelrebelo7@hotmail.com )

Universidade da Beira Interior https://orcid.org/0000-0002-4615-8220

João Serrano

Instituto Politecnico de Castelo Branco

Pedro Duarte-Mendes

Instituto Politecnico de Castelo Branco

Rui Paulo

Instituto Politecnico de Castelo Branco

Daniel Almeida Marinho

Universidade da Beira Interior

Research article

Keywords: Motor Development, Child development, Motor skills, Validation, PDMS-2

Posted Date: September 15th, 2020

DOI: https://doi.org/10.21203/rs.3.rs-66818/v1

License: (9) This work is licensed under a Creative Commons Attribution 4.0 International License.

Read Full License 


\section{Abstract}

Background: The purpose of this study was to examine the psychometric properties of Peabody Developmental Motor Scales II (PDMS-2 - Folio \& Fewell, 2000) using a Portuguese sample.

Methods: The validation of the Portuguese version of the PDMS-2 was applied according to the manual, for 392 children, from two institutions, from 12 to 48 months, with an analysis of the internal consistency (a Cronbach), of Temporal Stability (ICC) and Construct validity (confirmatory factor analysis).

Results: The results of the confirmatory factorial analysis $\left(\chi^{2}=55.614 ; \mathrm{df}=4 ; p=.06 ; \chi^{2} / \mathrm{df}=13.904\right.$; SRMR $=.065 ; \mathrm{CFI}=.99, \mathrm{TLI}=.99$, RMSEA $=.068$ ) of two factors (Gross Motor and Fine Motor) as the original version. Most of the subtests had good internal consistency $(\alpha=.85)$ and good test-retest stability (ICC $=$ .98 to .99$)$.

Conclusions: These results indicate that the Portuguese version of the PDMS-2 is an accurate and valid instrument to evaluate the gross and fine motor skills of children aged 12 to 48 months, can be used as a reference instrument by health and education professionals, as an indicator and support for the assessment of motor skills, thus having a assessment instrument that allows to detect maladjustments, deficiencies or precociousness, so that the child can later receive the appropriate intervention

\section{Background}

Motor development is a set of change processes that take place throughout life, especially in childhood and adolescence [1]. The same authors also consider that changes in movement and movement patterns change drastically during the first years of life, showing different rhythms of development from child to child, that is, a strong inter-individual variability and with differences from group to group.

Carvalho [2], says that at birth, all children are similar because they need care, progress according to a typical sequence of developmental stages, and learn appropriate social behaviors. However, the child becomes a unique being through socio-cultural influences, experiences and through its biological uniqueness [2]. In this sense, society and culture can have a profound effect on an individual's motor behaviors mainly through the practice of physical activity, as well as socio-cultural elements, such as family, gender, race, religion and nationality, can guide the future of a child's motor behavior [3], increasingly suggests, the need to understand these elements, through a motor assessment, with specific tools and instruments.

Among the various specific motor assessment tools and instruments described in the literature (AIMS, GMFM, HINT, IB, MABC-II, MFM, PEDI, TGMD-2), a Peabody Developmental Motor Scales - second edition (PDMS-2) [4] is one of the most used instruments in clinical and research settings [5] just as it has the ability to be applied right from the birth of the child. This standardized tool was applied to assess the fine and gross motor skills of children, from birth to 71 months of age and its normative sample was based on 2003 children residing in forty-six states in the United States and in a province of Canada. 
In its first edition [6], a PDMS was specially designed for the early detection of developmental delays or disturbances. The current revised version [4] has other advantages, which specifically allows: assessing the child's motor competence in relation to his peers; identify motor deficits and imbalances between the fine and gross motor domain; establish individual goals and objectives in clinical and / or educational intervention; and monitor the child's individual development. The same authors also highlight the usefulness of PDMS-2, as a research tool, proven with the use in several studies and research projects in the last decade.

The usefulness of PDMS-2 as an assessment tool is evident in several studies, which characterized the motor profile of special or clinical populations, such as: cerebral palsy, autism, Down syndrome and Hurler syndrome [7-11]. Nevertheless, PDMS-2 has been widely used to analyze the effects of biological (prematurity and malnutrition) and environmental (socioeconomic status, parents' educational qualifications, quality of the domestic environment, routines established by the family) on child development [12-23].

Its acceptance in the scientific community results from the fact that this instrument allows a multidimensional interpretation of motor behavior, through the calculation of the following motor composites: Gross Motor Quotient (GMQ), Fine Motor Quotient (FMQ), and the Total Motor Quotient (TMQ), what results from the first two. The segmentation of the TMQ has a very special interest for the differentiation of individual characteristics and, particularly, for the analysis of the effects of intervention programs [24].

According to Folio and Fewell [4], PDMS-2 is a significant improvement on the original version, with regard to the representativeness of the standards and their psychometric properties. In terms of instrument accuracy, the manual reports a good index of internal consistency for each subtest ( $a=.89$ to .95 ) and for each motor quotient (.96 to .97), acceptable temporal stability, through the test-retest with an interval of one week ( $a=.73$ to .96 depending on the age level) e high inter-observer fidelity, which varied between .97 to .99 for subtests and between .96 and .98 for the motor quotients. With regard to its construct validity, the two confirmatory factorial studies carried out, with two North American gauging sub-samples (up to 11 months and between 12 and 72 months) identified a measurement model, consisting of two factors - Fine Motor (FM) e Gross Motor (GM), defined respectively by two subtests of fine motor skills (Visual-Motor Integration and Grasping) and three gross motor skills subtests (Stationary, Locomotion, Object Manipulation, or Reflexes, in the case of children up to eleven months of age). In another study with Taiwanese children, developed by Chien e Bond [25], when specifically analyzing the dimensionality of the fine motor scale through the Rasch model (1960), concluded that the reduction of some items and the grouping of their two tests (Visual-Motor Integration and Grasping) would make the scale more consistent and more clinically useful. These results show that the validated measurement model, for the North American sample, may not be suitable or identical for another distinct population, so it is prudent to proceed with its cross-cultural adaptation before application [25]. Regarding concurrent validity, the authors of the instrument [4] concluded that as PDMS-2, presenting a high 
correlation with its original version ( $\mathrm{a}=.84$ and .91 respectively for GMQ and FMQ) and with the Mullen Scales of Early Learning (Mullen, 1995) ( $\mathrm{a}=.86$ and .80 respectively for GMQ and FMQ).

Also Bean et al. [26], when assessing children at risk of development, aged between two and fifteen months, registered good rates of internal consistency ( $a=.90$ and .97 ) between the results of three subtests (Reflexes, Stationary and Locomotion) the PDMS-2 gross motor scale and the total motor quotient of the Alberta Infant Motor Scale [27]. In its turn, Connolly et al. [28], analyzed the concurrent validity between PDMS-2 and Bayley Scales of Infant Development II (BSID-II) with 12 month old children. The results showed a low correlation between the standard values of the motor quotients the PDMS-II and the Psychomotor Development Index of the BSID-II ( $\alpha=.30 ; .22$ and .32 respectively for GMQ, FMQ e TMQ). Only a high correlation was found in the values referring to age for the Locomotion test ( $a=.71, p$ $<.05)$. Based on these results, Bean et al. [26] advise prudence in the interpretation of standardized values or values referring to age, when making clinical decisions based on a single assessment instrument..

The sensitivity of the instrument was confirmed by the authors of the scales [4], depending on age, sex, ethnicity (European Americans, African Americans and Hispanic Americans) and motor and mental deficits. Additionally, Wang, Liao and Hsieh [29], they also tried to test the sensitivity in a sample of children with cerebral palsy, aged between two and five years, the results suggest a sensitivity to developmental changes for an interval of six months. This appears to be an important improvement on the revised version, since Palisano et al. [30] had reported that the gross motor scale, of the original version of the PDMS, was not able to detect changes in the motor development of children with cerebral palsy, in an interval of six months.

Despite all the metric evidence, some authors [31-34] have warned that the application of PDMS-2, and particularly the interpretation of its standardized values, for certain special / clinical groups or in contexts culturally different from those for which the instrument was originally developed, should be developed with some caution, and recommend a cross-cultural adaptation and validation of the instrument to the population concerned. Regarding the reliability of the instrument for the Portuguese population, Saraiva et al. [24], reported in their adaptation and validation study, that most subtests had a good index of internal consistency ( $\alpha=.76$ to .95 ) and good test-retest stability (ICC $=.85$ to .95 ), concluding that the results indicate that the Portuguese version of PDMS-2 is an accurate and valid instrument for assessing the gross and fine motor skills of Portuguese children of pre-school age (from 36 to 72 months). However Saraiva et al. [24] refer that it is essential to replicate the same study, in different age groups, highlighting the age range from 0 to 36 months.

Thus, as an indicator and support for the assessment of motor skills by health and education professionals, it is pertinent to verify whether the PDMS-2 scales are suitable for the Portuguese population aged 12 to 48 months, so that it can be used as assessment instrument that allows to detect maladjustments, deficiencies or precociousness, and the child can later receive the appropriate intervention. 
In this sense, the objective of the study was to analyze the psychometric properties of the Portuguese version of Peabody Developmental Motor Scales II (PDMS-2) for the Portuguese population from 12 to 48 months.

According to the existing literature, $[3,24,35]$, it is expected that the Portuguese version of PDMS-2 will present psychometric properties similar to those of the original version in terms of its characterization, precision and theoretical construct, and that it will be an accurate and valid instrument to assess the gross and fine motor skills of Portuguese children aged 12 at 48 months.

\section{Method}

\section{Participants}

This study fits into a quantitative correlational typology, being a cross-sectional study. As for the nature of the sample, we can say that it is intentional, for convenience, since it is appropriate to the type of study we intend to carry out and we consider it to be non-probabilistic, since it was selected by the researcher's subjective criteria and according to the purpose of the study [36].

The study, took place in nurseries and kindergartens, and consisted of a total of 392 subjects of both genders with ages (29.86 \pm 8.79 months) understood between 12 and 47 months (Male, $n=199,29.94 \pm$ 8.73 months; Femine, $n=193,29.78 \pm 8.87$ months) from public and private institutions, from urban, semiurban and rural areas in the district of Castelo Branco, Portugal.

For the selection of the sample, the following inclusion criteria were defined: children aged between 12 and 48 months; and be of Portuguese nationality; And as as exclusion criteria: children diagnosed with learning difficulties and / or developmental impairments and / or children with some type of diagnosed disability, respectively.

All ethical principles, international norms and standards regarding the Helsinki Declaration and the Convention on Human Rights and Biomedicine were followed, respected and preserved [37]. This project was approved by the Ethics Committee of the institution where the authors carry out their research.

The Table 1 summarizes the main sociodemographic characteristics of the sample by age group.

\section{Table 1.}

\section{Sociodemographic characterization of the 392 Portuguese children}




\begin{tabular}{|c|c|c|c|c|c|}
\hline & & $\begin{array}{l}12-23 \\
\text { Months } \\
(n=96)\end{array}$ & $\begin{array}{l}24-35 \\
\text { Months } \\
(n=153)\end{array}$ & $\begin{array}{l}36-47 \\
\text { Months } \\
(n=143)\end{array}$ & $\begin{array}{l}\text { Totals } \\
(n=392)\end{array}$ \\
\hline $\begin{array}{l}\text { Age (Average } \pm \\
\text { SD) }\end{array}$ & & $18.66 \pm 3.91$ & $28.07 \pm 3.35$ & $39.30 \pm 3.55$ & $\begin{array}{l}29.86 \pm \\
8.79\end{array}$ \\
\hline Genre, N (\%) & Male & $44(45.8)$ & 79 (51.6) & $76(51.6)$ & $199(50.8)$ \\
\hline Feminine & $\begin{array}{l}52 \\
(54.2)\end{array}$ & $74(48.4)$ & $67(48.4)$ & 193 (49.2) & \\
\hline Residence (\%) & Urban & $60(62.5)$ & $132(86.3)$ & 125 (87.4) & 317 (80.9) \\
\hline SemiUrban & $\begin{array}{l}21 \\
(15.6)\end{array}$ & $3(2.0)$ & $16(11.2)$ & $40(10.2)$ & \\
\hline Rural & $\begin{array}{l}15 \\
(21.9)\end{array}$ & $18(11.8)$ & $2(1.4)$ & $35(8.9)$ & \\
\hline
\end{tabular}

Note. $n=392$.

\section{Instruments}

Studies with PDMS-2 were authorized by the publisher PRO-ED, from Austin, Texas. In this process, we tried to follow the methodological procedures, recommended in the specific literature regarding the adaptation of an evaluation instrument $[38,39]$ since all the translation processes of the instrument had already been carried out by Saraiva, Rodrigues, and Barreiros [24], having adopted all the procedures that aimed to ensure linguistic, conceptual, operational and psychometric equivalence between the translated Portuguese version and the original version.

Every version of the PDMS-2 was translated by Saraiva et al. [24] but it was only applied to children aged 36 to 71 months. Thus, based on the Portuguese version of the PDMS-2, it was applied to 392 children from 12 to 48 months, age group not applied by the authors of the first adaptation and validation for the Portuguese population (from 12 to 36 months).

The composite structure of the PDMS-2 includes five subtests distributed over two motor components / scales: gross motor skills and fine motor skills. Its results are expressed in three domains of motor behavior: Fine Motor Quotient (FMQ), o Gross Motor Quotient (GMQ) and total motor quotient (TMQ), the latter resulting from the first two. The FMQ is found by the sum of two sets of subtests, namely, Grasping and Visual-Motor Integration, while for the GMQ three are used: Stationary, Locomotion and Object Manipulation (the latter is replaced by the Reflexes subtest for children up to eleven months old). Each of these subtests consists of items (motor tasks) adjusted for age and placed in an increasing sequence of difficulties. The child starts the test on a specific item, according to his age, and continues in the sequence until three consecutive runs fail. 
Each item is classified according to an evaluation scale, of three values: $0=$ does not perform, $1=$ minimum proficiency, 2 = optimal proficiency. The sum value of all items, in each of the subtests, is located in the reference table for age, resulting in a standardized value and a percentage value that can be compared between ages. Subsequently, the sum of the standardized values of the grouped subtests, allows obtaining the total motor quotient, fine or gross, by consulting a second table. The standardized scales for the North American child population establish the average value of 10 points $( \pm 3)$ for each test and the average value of 100 points $( \pm 15)$ for the motor quotients. Standardized values can also be converted into a qualitative classification of seven categories (between "Very Good" and "Very Weak") [24].

\section{Procedures}

After approval by the institutions, the necessary authorizations were obtained, and informed consent was also requested from the guardians, whom all the procedures and the purpose of the study were explained.

The children were assessed individually, by two specially trained investigators, with a percentage of $90 \%$ interobserver agreements reached, in the item-by-item quotation before data collection. The administration of the scales took about 30 to 45 minutes per child, depending on the age group. The evaluation took place in a kindergarten room, in a non-intrusive environment and adequate to the protocol described in the PDMS-2 manual [4]. The raw scores, obtained in the subtests, were converted into standard scores, and the respective gross, fine and total motor quotients were calculated, based on the values referenced in the manual.

Statistical analysis

Initially, measures of central tendency (mean) and measures of dispersion (standard deviation) were analyzed, as well as bivariate correlations between all variables analyzed. In a second instance, in order to respond to the objective of the present study, a Confirmatory Factor Analysis was performed (CFA). To carry out the CFA, the recommendation of a ratio was considered 10:1 (i.e., number of subjects for each parameter to be estimated in the model) suggested by several authors [40-45]. Data analysis was performed according to the guidelines and recommendations of several authors [40,42,44]: in addition to the maximum likelihood estimation method (MLE), through the chi-square test $\left(\chi^{2}\right)$ the respective degrees of freedom $(d f)$ and the level of significance $(p)$ the following adjustment quality indices were also used: Standardized Root Mean Square Residual (SRMR), Comparative Fit Index (CFI), Non-Normed Fit Index (NNFI), Root Mean Square Error of Approximation (RMSEA) and the respective confidence interval (90\% $\mathrm{CI})$. In the present study, for the referred indices, cut-off values were adopted, suggested by Byrne $[40,41]$; Hair et al. [42,43] and Marsh, Hau and Wen [46]: SRMR $\leq .08, \mathrm{CFI}$ and NNFI $\geq .90$ and RMSEA $\leq .08$. Convergent validity was also analyzed (to check if the items are related to the respective factor), through average variance extracted (AVE) calculation, considering adjusted values of AVE $\geq .50[12,13,17]$ and the Discriminant validity was verified (to verify that the factors are sufficiently distinct from each other), considering adjusted with the square of the correlation between the factors is less than the value of AVE on both factors [42], as well as, the composite reliability (CR), to evaluate the internal consistency of the 
factors, adopting as cut-off values $\geq .70$ de CR, as suggested by Hair et al. [42]. The data were analyzed using the software AMOS 23.0.

\section{Results}

\section{Preliminary Analysis}

A preliminary analysis of the data revealed that there were no missing values, univariate and multivariate outliers. The results also revealed that there were no violations to the univariate normal distribution, since the values of Skewness and Kurtosis were included between $-2+2$ e - $7+7[40,41]$, respectively.

Notwithstanding, Mardia's coefficient for multivariate kurtosis revealed a normal multivariate distribution (2.618), this value is lower than that recommended in the literature (5.0), as suggested by several authors $[42,43]$, so no measures were taken against multivariate non-normality [41].

Table 2 shows the descriptive analysis of the raw scores and the sub-tests according to the age group. In a brief analysis of the data, it is confirmed that the average values obtained in each sub-test, register a desired increase over the age groups, which is evidence of the characterization of the sample. The expected variability of the results is also visible in all subtests, except in the Grasping test, which only records a standard deviation of 1.7 and 2.7 in the two and three year age groups, respectively

\section{Table 2.}

Mean, standard deviation (SD), minimum-maximum value and amplitude of the Raw scores, obtained in the sub-tests by age group 


\begin{tabular}{|c|c|c|c|c|}
\hline Subtests & & $\begin{array}{l}12-23 \text { Months } \\
(n=96)\end{array}$ & $\begin{array}{l}24-35 \text { Months } \\
(n=153)\end{array}$ & $\begin{array}{l}36-48 \text { Months } \\
(n=143)\end{array}$ \\
\hline Stationary & Mean (SD) & $39.4(2.3)$ & $43.3(2.8)$ & $48.9(3.8)$ \\
\hline Min - Max* & $36-46^{*}$ & $38-51^{*}$ & $41-56^{*}$ & \\
\hline Amplitude & 10 & 13 & 15 & \\
\hline Locomotion & Mean (SD) & $81.4(13.5)$ & $111.6(13.5)$ & $137.8(10.1)$ \\
\hline Min - Max* & $50-100 *$ & $87-136 *$ & $115-158 *$ & \\
\hline Amplitude & 50 & 49 & 43 & \\
\hline Object Manipulation & Mean (SD) & $13.2(5.5)$ & $21.1(5.8)$ & $30.0(5.1)$ \\
\hline Min - Max* & $1-26 *$ & $8-35^{*}$ & $20-42^{*}$ & \\
\hline Amplitude & 25 & 27 & 22 & \\
\hline Grasping & Mean (SD) & $39.9(3.8)$ & $43.3(1.7)$ & $48.2(2.7)$ \\
\hline Min - Max* & $34-46^{*}$ & $40-47^{*}$ & $42-52^{\star}$ & \\
\hline Amplitude & 12 & 7 & 10 & \\
\hline Visual-Motor Integration & Mean (SD) & $79.7(9.83)$ & $99.9(11.1)$ & $121(8.8)$ \\
\hline Min - Max* & $53-96 *$ & $79-122 *$ & 109-139* & \\
\hline Amplitude & 43 & 43 & 30 & \\
\hline
\end{tabular}

Note. * Maximum possible score: Stationary $(n=60)$; Locomotion $(n=178)$; Object Manipulation $(n=48)$; Grasping ( $n=52)$; Visual-Motor Integration $(n=144)$.

\section{Precision Study}

The Precision Study of the instrument, included the analysis of the internal consistency of the subtests and the temporal stability of the results obtained, by thirty children in our sample after a retest in an interval of seven days. Table 3 shows the results for these precision parameters.

\section{Table 3.}

Internal consistency and temporal stability of subtests 


\begin{tabular}{|lll|}
\hline Subtest & Internal Consistency (a Cronbach) $\mathrm{n}=\mathbf{3 9 2}$ & $\begin{array}{l}\text { Temporal Stability (ICC) } \\
\mathrm{n}=\mathbf{3 0}\end{array}$ \\
\hline Stationary & .86 & .98 \\
\hline Locomotion & .97 & .99 \\
\hline Object Manipulation & .93 & .98 \\
\hline Grasping & .84 & .99 \\
\hline Visual-Motor Integration & .96 & .99 \\
\hline
\end{tabular}

Note. ICC $\geq .98$

By interpreting Cronbach's alpha values, it can be said that most subtests obtained a good internal consistency index, oscillating between .84 and .97. The subtests recorded excellent values for internal consistency of Locomotion ( $\mathrm{a}=.97)$, Object Manipulation ( $\mathrm{a}=.93)$, and the Visual-Motor Integration $(a=.96)$, and good values internal consistency and good values internal consistency the Stationary $(\mathrm{a}=.86)$ and the Grasping $(\mathrm{a}=.84)$. With regard to the temporal stability estimated through the intraclass correlation coeficiente (ICC), it can be seen in Table 3 that the values varied between .98 and .99.

\section{Construct validity}

The PDMS-2 factorial model tested for the Portuguese sample was identical to the one originally proposed by the authors (Figure 1); that is, a model of two latent factors (gross motor skills and fine motor skills) defined respectively by three (Stationary, Locomotion and Object Manipulation) of gross motor skills and two (Grasping and Visual-Motor Integration) items of fine motor skills. Its adjustment was tested through a confirmatory factor analysis.

\section{Figure 1.}

Factorial structure of the PDMS-2 measurement model for the Portuguese sample aged between 12 and 48 months

By analyzing the figure 1, it appears that all items have a factor weight $\geq .50$ (all statistically significant, $p<.05)$, etherefore explaining at least $25 \%$ of the latency factor variance $[42,43]$. Additionally, the measurement model revealed good values of convergent validity, since the AVE of both factors was higher than .50 [47]. However, the instrument revealed problems of discriminant validity, since the square of the correlation between the factors $\left(r^{2}=.96\right)$ was higher than the AVE value on both factors $(.82 ; .80)$, for the gross motor and fine motor factors, respectively. Finally, the instrument revealed good values of internal consistency, since the values of composite reliability of both factors were higher than .70 $[42,43,48]$.

Table 4. 
Adequacy indexes of the model tested between 12 and 47 months

\begin{tabular}{|llllllll|}
\hline Index & $\chi^{2}$ & $\chi^{2} /$ DF & SRMR & TLI & CFI & RMSEA & $90 \%$ IC \\
\hline M 1 & 55.614 & 13.904 & .065 & .992 & .998 & 0.68 & $0.000-.138$ \\
\hline
\end{tabular}

Based on table 4, it turns out that the the measurement model of the analyzed instrument presented a good adjustment to the data, according to the cut-off values adopted in the methodology $[40-13,46]$.

\section{Discussion}

The aim of the present study was to analyze the psychometric properties of the Portuguese version of Peabody Developmental Motor Scales II (PDMS-2) for the Portuguese population from 12 to 48 months. In the preliminary analysis, the data revealed that there were no missing values, nor univariate and multivariate outliers, and that there were no violations of the univariate normal distribution. The results showed in the study of the accuracy of the instrument, that the Portuguese version PDMS-2 revealed, on the whole, very satisfactory indexes. As well as it presented good indexes of adjustment in the confirmatory factor analysis.

\section{Preliminary Analysis}

In the sample characterization study, it was confirmed that the subtests of Visual-Motor Integration, Stationary, Locomotion and Object Manipulation were able to discriminate the motor performance of Portuguese children between the ages of 12 and 48 months. The average scores (raw scores) of these subtests registered an increase over age and their respective standard deviations (greater than 2.3) prove the variability of the results obtained in the study sample as it had already happened in the study by Saraiva et al. [24].

The same cannot be said in relation to the Grasping subtest, since the raw scores achieved by the two year old children only showed a variability of 1.7 . In fact, this seems to be really a limitation of the instrument, regardless of the population concerned, as this result was also reported for Taiwanese children [25], Flemish [49] and Portuguese [24] in preschool age. From a clinical point of view, Van Hartingsveldt, Cup e Oostendorp [34], to when evaluating eighteen Dutch children aged four and five, they concluded that the fine motor skills scale of the PDMS-2 demonstrated a lower sensitivity to discriminate children with slight fine motor problems compared to the Movement Assessment Battery for Children.

\section{Precision Study}

Regarding the Precision Study of the instrument, it can be inferred that the Portuguese version PDMS-2 showed, on the whole, very satisfactory and comparable indexes to the original version, such as Saraiva et. al. [24] had already achieved but as different ages. All subtests reached an alpha Cronbach value substantially higher than the cut-off point of .70 proposed by Hair et al. [42]. 
In terms of test-retest accuracy, it was found that the subsample of thirty Portuguese children, in an interval of seven days between the two applications, also registered high stability coefficients (ICC $\geq .98)$ in all subtests. These PDMS-2 accuracy indexes have been confirmed in other psychometric studies $[10,24,29,34,50,51]$.

\section{Construct validity}

As for the construct validity, the results of the confirmatory factor analysis support that the Portuguese version PDMS-2 presents a model of two factors: gross motor and fine motor, just like the original version proposed by Folio e Fewell [4]. The adjustment indexes of the Portuguese model from 12 to 48 months $\left(\chi^{2}=55.614, \mathrm{df}=4, p=.06\right)$ and $\mathrm{SRMR}=0.065 ; \mathrm{TLI}=0.992 ; \mathrm{CFI}=0.998 ;$ and RMSEA $=.06890 \% \mathrm{IC}=0.000$ .138) were very similar to the Portuguese model from 36 to 71 months for Saraiva, et. al. [24], (S-BX2=3.3, $\mathrm{p}=.349 ; \mathrm{CFI}=1.0 ; \mathrm{NFI}=.99 ; \mathrm{NNFI}=.99 ; \mathrm{RMSEA}=.013$ ) and those of the original North American version (TLI=.96; RMSEA=.08). Finally, is to highlight that the Portuguese factorial structure from 12 to 48 months registered higher values of item-factor saturation ( $a=.81$ to .99 ), compared to the Portuguese factorial structure from 36 to 71 months ( $a=.67$ to .95 ) and the original American structure ( $a=.54 a .89)$ respectively, which demonstrates a greater relevance of the values of the items (subtests) in the determination of the respective latent factors (gross motor and fine motor).

\section{Study Limitations}

Among this study's limitations is the fact that the research design is transversal, with the evaluation and data collection with children of a premature age group, quite time consuming, as well as the entire process of adaptation and validation of the evaluation instrument.

\section{Conclusions}

In short, we can conclude that the Portuguese version PDMS-2 proved to be an accurate and valid instrument to assess the fine and global motor skills of Portuguese children in children aged 12 to 48 months. The different empirical analyzes conducted in the scope of this study have shown that the Portuguese version has psychometric characteristics similar to those of the original version in terms of its characterization, precision and theoretical construct, which enables its use and credibility in the national context, which is important in the fields educational, clinical and scientific.

It is suggested, in future studies, to take advantage of the instrument's potential, that the process of validation and measurement of the PDMS-2 be consolidated with the replication of the same study, for the Portuguese population, particularly with the unexplored age groups (from zero to 1 year).

\section{Practical Applications}

The results obtained by our study suggest that the PDMS-2 scales can be used as a reference instrument by health and education professionals, as an indicator and support for the assessment of motor skills, 
thus having a assessment instrument that allows to detect maladjustments, deficiencies or precociousness, so that the child can later receive the appropriate intervention. However, it is important to emphasize that the acquisition of skills is not directly and intrinsically linked to time, but to the development process that is unique to each human being [52].

\section{Declarations}

\section{Ethics approval and consent to participate}

All ethical principles, international norms and standards regarding the Helsinki Declaration and the Convention on Human Rights and Biomedicine were followed, respected and preserved (Tuckman 2000). This project was approved by the Ethics Committee of the University of Beira Interior, Covilhã, Portugal, with the reference number (CE-UBI-Pj-2018-051:ID739), and the written informed consent was obtained from a parent or guardian for participants under 16 years old.

\section{Consent for publication}

Informed consent was obtained from all individual participants included in the study, from legal guardians or parents.

\section{Availability of data and materials}

The datasets generated and/or analysed during the current study are not publicly available due [REASON WHY DATA ARE NOT PUBLIC] but are available from the corresponding author on reasonable request.

\section{Competing interests}

The authors declare that they have no competing interests

\section{Funding}

Not applicable

\section{Authors' contributions}

Conceptualisation, R.M. and S.J.; Data curation, M-D.P.; Formal analysis, S.J. and P.R.; Investigation, R.M. and P.R.; Supervision, M-D.P. and M.A-D.; Methodology, M-D.P.; writing-original draft preparation, R.M. and M.A-D.; writing-review and editing, S.J. and M.A-D. All authors read and approved the final manuscript.

\section{Acknowledgements}

Not applicable

\section{References}


1. Barreiros J, Neto C. O Desenvolvimento Motor e o Género. Lisboa: Edições FMH; 2007.

2. Carvalho D. A competência motora fina da criança em idade pré-escolar: um estudo exploratório. Viana do Castelo: Escola Superior de Educação do Instituto Politécnico de Viana do Castelo; 2007.

3. Fernandes M. Estudo Exploratório da Peabody Developmental Motor Scales-2 (PDMS-2), dos 36 aos 71 meses de idade. Dissertação de Mestrado, Faculdade de Motricidade Humana; 2011.

4. Folio R, Fewell R. Peabody Developmental Motor Scales-2. Austin: TX: Pro-Ed;; 2000.

5. Saraiva L, Rodrigues L. Peabody developmental motor scales-2 (PDMS-2): definição e aplicabilidade no contexto educativo, clínico e científico. In: Barreiros J, Cordovil S, Carvalheiro S, editors. Desenvolvimento Motor da Criança. Lisboa: Edições FMH; 2007. pp. 285-92.

6. Folio R, Fewell R. Peabody Developmental Motor Scales and Activity Cards Manual. Allen: Tex: DLM Teaching Resources; 1983.

7. Dusing SC, Thorpe D, Rosenberg A. Gross motor abilities in children with Hurler syndrome. Development Medicine Child Neurology. 2006;48(Suppl 11):927-30.

8. Maring JR, Courcelle-Carter KJ. Comparison of Gross Motor Subtest scores of the Peabody Developmental Motor Scale-2 in children with Down Syndrome. Pediatrics Physical Therapy. 2004;16(Suppl 1):49-68.

9. Mitchell WG, Brumm VL, Azen CG, Patterson KE, Aller SK, Rodriguez J. Longitudinal neurodevelopmental evaluation of children with opsoclonus-ataxia. Pediatrics. 2005;116(Suppl 4):901-7.

10. Provost B, Lopez B, Heimerl SA. Comparison of motor delays in young children: autism spectrum disorder, developmental delay, and developmental concerns. Journal Autism Developmental Disorders. 2007;37(Suppl 2):321-8.

11. Smith M, Danoff J, Parks R. Motor skills development of children with HIV infection measured with Peabody Developmental Motor Scale. Pediatric Physical Therapy. 2002;14(Suppl 2):74-84.

12. Angelsen N, Jacobsen G, Bakketeig LS. Breast feeding and cognitive development at age 1 and 5 years. Archives Disease in Childhood. 2001;85(Suppl 3):183-8.

13. Arendt R, Angelopoulos J, Salvator A, Singer L. Motor development of cocaineexposed children at age two years. Pediatrics. 1999;103:86-92.

14. Evensen KAl, Skranes J, Brubakk AM, Vik T. Predictive value of early motor evaluation in preterm very low birth weight and term small for gestational age children. Early Hum Dev. 2009;85(Suppl 8):5118.

15. Fetters L, Tronick E. Neuromotor development of cocaine-exposed and control infants from birth through 15 months: poor and poorer performance. Pediatrics. 1996;98(Suppl 5):938-43.

16. Majnemer A, Barr RG. Association between sleep position and early motor development. The Journal of Pediatric. 2006;149(Suppl 5):623-9.

17. Miller-Loncar C, Lester BM, Seifer R, Lagasse LL, Bauer CR, Shankaran S, et al. Predictors of motor development in children prenatally exposed to cocaine. Neurotoxicol Teratol. 2005;27(Suppl 2):213- 
20.

18. Goyen T, Lui K. Longitudinal motor development of "apparently normal" high-risk infants at 18 months, 3 and 5 years. Early Human Dev. 2002;70:103-15.

19. Nelson S, Lerner E, Needlman R, Salvator A, Singer L. Cocaine, anemia, and neurodevelopmental outcomes in children: a longitudinal study. Developmental Behavioral Pediatrics. 2004;25:1-9.

20. Trasti N, Vik T, Jacobsen G, Bakketeig LS. Smoking in pregnancy and children's mental and motor development at age 1 and 5 years. Early Hum Dev. 1999;55(Suppl 2):137-47.

21. Sommerfelt K, Sonnander K, Skranes J, Andersson HW, Ahlsten G, Ellertsen B, et al. Neuropsychologic and motor function in small-for-gestation preschoolers. Pediatr Neurol. 2002;26(Suppl 3):186-91.

22. Rodrigues L. Development and Validation of the AHEMD-SR affordances in the home environment for motor development-self report. PhD Thesis (Doctor of Philosophy) Texas A\&M University: College Station. 2005.

23. Santos D, Tolocka R, Carvalho J, Heringer L, Almeida C, Miquelote A. Desempenho motor grosso e sua associação com fatores neonatais, familiares e de exposição à creche em crianças até três anos de idade. Revista Brasileira de Fisioterapia. 2009;13:173-9.

24. Saraiva L, Rodrigues LP, Barreiros J. Adaptação e validação da versão portuguesa Peabody Developmental Motor Scales-2: um estudo com crianças préescolares. The Journal of Physical Education/UEM. 2011;22(Suppl 4):511-21.

25. Chien C, Bond T. Measurement properties of fine motor scale of Peabody Development Motor Scalessecond edition: Rasch Analysis. Am J Phys Med Rehabil. 2009;88(Suppl 5):376-82.

26. Bean J, Breaux G, Hymel E, Kinler E, Monti D, Rome B, et al. Concurrent validity of the Alberta Infant Motor Scale (AIMS) and the Peabody Developmental Motor Scale II (PDMS-II). Pediatric Physical Therapy. 2004;16:49-50.

27. Valentini N, Saccani R. Escala Motora Infantil de Alberta: validação para uma população gaúcha. Revista Paulista de Pediatria. 2011;29(Suppl 2):231-8.

28. Connolly BH, Dalton L, Smith JB, Lamberth NG, McCay B, Murphy W. Concurrent validity of the Bayley Scales of Infant Development II (BSID-II) Motor Scale and the Peabody Developmental Motor Scale II (PDMS-2) in 12-Month-Old Infants. Pediatric Physical Therapy. 2006;18(Suppl 3):190-6.

29. Wang $\mathrm{H}$, Liao H, Hsieh C. Reliability, sensitivity to change, and responsiveness of the Peabody Developmental Motor Scales-second edition for children with Cerebral Palsy. Phys Ther. 2006;86(Suppl 10):1351-9.

30. Palisano RJ, Kolobe TH, Haley SM, Pax Lowes L, Jones SL. Validity of the Peabody Developmental Gross Motor Scale as an evaluative measure of Infants receiving physical therapy. Phys Ther. 1995;75(Suppl 11):939-48.

31. Crowe T, Mcclain C, Provost B. Motor Development of Native American children on the Peabody Developmental Motor Scales. The American Journal of Occupational Therapy. 1999;53(Suppl 5):514-8. 
32. Provost B, Heimerl S, McClain C, Kim NH, Lopez BR, Kodituwakku P. Concurrent Validity of the Bayley Scales of Infant Development II Motor Scale and the Peabody Developmental Motor Scales-2 in children with developmental delays. Pediatric Physical Therapy. 2004;16:149-56.

33. Tripathi R, Joshua AM, Kotian MS, Tedla JS. Normal motor development of Indian children on Peabody Developmental Motor Scales-2 (PDMS-2). Pediatric Physical Therapy. 2008;20(Suppl 2):167-72.

34. Van Hartingsveldt M, Cup E, Oostendorp R. Reliability and validity of the fine motor scale of the Peabody Developmental Motor Scales-2. Occupational Therapy International. 2005;12:1-13.

35. Leitão P. Contributo para a validação de uma escala pediátrica, Peabody Developmental Motor Scale-2 (versão Portuguesa). Dissertação de Mestrado, Instituto Politécnico de Lisboa. 2014.

36. Tuckman B. Manual de Investigação em Educação Lisboa, Fundação Calouste Gulbenkian. 1994.

37. Tuckman B. Manual de Investigação em Educação. Fundação Calouste Gulbenkian. 2000.

38. Hambleton RK, Merenda P, Spielberger C. Adapting educational and psychological tests for crosscultural assessment. Hillsdale: Lawrence S. Erlbaum Publishers; 2005.

39. AERA. APA. NCME. Standards for educational and psychological testing. Washington, D.C.: Author. 1999.

40. Byrne B. Structural equation modeling with AMOS. Basic concepts, 529 applications, and programming (2nd ed.). New York: Taylor \& Francis Group, 530 LLC. 2010.

41. Byrne B. Structural equation modeling with AMOS. Basic concepts, 532 applications, and programming (3rd ed.). New York: Taylor \& Francis Group, 533 LLC. 2016.

42. Hair JF, Black W, Babin B, Anderson R. Multivariate data analysis. 7th ed. Upper Saddle River: Prentice Hall; 2014.

43. Hair JF, Ringle CM, Gudergan SP, Fischer A, Nitzl C, Menictas C. Partial least squares structural equation modeling-based discrete choice modeling: An illustration in modeling retailer choice. Bus Res. 2019;12:115-42.

44. Kline R. Principles and practices of structural equation modeling. New York: The Guilford Press; 2011.

45. Kline R. Principles and practice of structural equation modelling (3rd ed.). New 579 York, The Guildford Press. 2016.

46. Marsh H, Hau K, Wen Z. In search of golden rules: Comment on hypothesis testing approaches to setting cutoff values for fit indexes and dangers in overgeneralizing Hu and Bentler's (1999) findings. Struct Equ Model. 2004;11(Suppl 3):320-41.

47. Fornell C, Larcker D. Evaluating structural equation models with unobservable variables and measurement error. J Mark Res. 1981;18(Suppl 1):39-50.

48. Raykov T. Estimation of composite reliability for congeneric measures. Appl Psychol Meas. 1997;21(Suppl 2):173-84. 
49. Vanvuchelen M, Mulders H, Smeyers K. Onderzoek naar de bruikbaarheid van de recente Amerikaanse Peabody Developmental Scales-2 voor vijfjarige, Vlaamse kinderen. Signaal. 2003;45:24-41.

50. Kolobe T, Bulanda M, Susman L. Predicting Motor outcome at preschool age for infants tested at 7 , 30,60 , and 90 days after term age using the test of infant motor performance. Phys Ther. 2004;84(Suppl 12):1144-56.

51. Li-Tsang CW, Lee HC, Hung LK. Validation of chopsticks manipulation test for screening Chinese with fine motor dysfunction. Hong Kong Journal of Paediatrics. 2006;11(Suppl 2):103-9.

52. Souza SC, Leone C, Takano OA, Moratelli HB. Desenvolvimento de pré-escolares na educação infantil em Cuiabá, Mato Grosso, Brasil. Cad Saúde Pública. 2008.

\section{Figures}

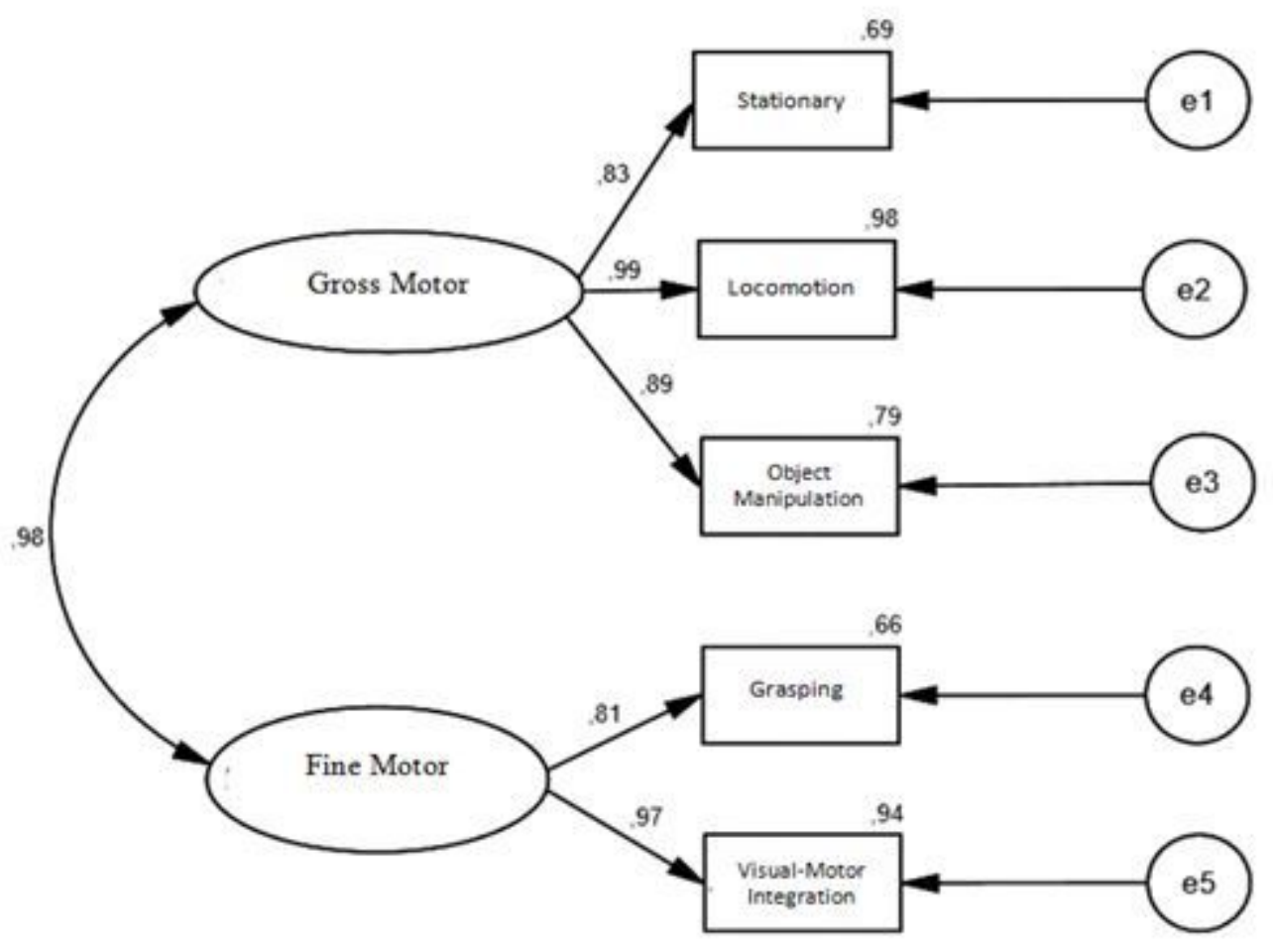

Figure 1

Factorial structure of the PDMS-2 measurement model for the Portuguese sample aged between 12 and 48 months 